\title{
A STUDY ON GENDER DIFFERENCES AND RELATIONSHIP BETWEEN SPIRITUAL BELIEF AND JOB SATISFACTION
}

\author{
VENUGOPAL N. ${ }^{1} \&$ H. S. ASHOK ${ }^{2}$ \\ ${ }^{I}$ Research, Department of Psychology, Bangalore University, Bengaluru, Karnataka, India \\ ${ }^{2}$ Chair Person, Department of Psychology, Bangalore University, Bengaluru, Karnataka, India
}

\begin{abstract}
The purpose of the present study was to study the relationship between spirituality and the level of job satisfaction among the employees working in educational and manufacturing sectors. The sample consisted of 200 employees from various sectors such as Education and Manufacturing sectors. Purposive sampling technique was used to collect the data. The sample was administered Spiritual Index scale and job satisfaction scale developed by Mahendran P. and Singh and Sharma respectively. The descriptive statistics, ' $t$ ' test and correlation test were used to verify the hypotheses. The findings reveal that there is a significant relationship between Spirituality or spiritual belief and the job satisfaction. Further study revealed that there are no gender differences in experiencing Job satisfaction and spirituality or spiritual belief except two dimensions of spirituality i.e., Transcendence and Religiousness where in females are more into the above-mentioned dimensions of spirituality than males.

KEYWORDS: Job Satisfaction, Transcendence, Belongingness, Self-esteem, Naturalness \& Religiousness
\end{abstract}

Received: Dec 19, 2018; Accepted: Jan 09, 2019; Published: Feb 01, 2019; Paper Id.: IJESRAPR20191

\section{INTRODUCTION}

The present world is running through a phase in which every belief and values are put under the scan to find their relevance, reliability and the effect on our routine life. In today's scenario it is very challenging to be satisfied in the working place. Organizations and people are looking for a means through which they could enhance their satisfaction level, especially at the working place.

Work place Spirituality or spiritual belief is such important psychological phenomenon that people are looking for some positive effect on their work life. Under the shadow of spirituality or being spiritual an individual can be satisfied and happy at work. The current industrial set ups are very keen on taking up this spiritual practice as a tool to enhance their employees' satisfaction level in the work.

Spirituality can be defined as "the basic feeling of being connected with one's complete self, others and the entire universe" (Collins, 2006). However, the work place spirituality held a new dimensional meaning as "expressing our desires to find meaning and purpose in our lives and is a process of living out one's set of deeply held personal values" (Neck and Milliman,1994).

Spirituality can be understood in terms of "Transcendence, Belongingness, self-esteem, Naturalness and Religiousness., whereas Transcendence is 'The feeling state of being with the constant remembrance of the supreme soul', Belongingness is 'The feeling state of being that everyone in this world belongs to each other', Self-esteem is 'the feeling state of being self-worth', Naturalness is 'The feeling state of being with the nature or 
environment' and Religiousness is ' The feeling state of being religious'(Dr. Mahendran. P).

Job satisfaction can be defined as "Job satisfaction represents the combination of positive or negative feeling that the workers have towards their work" (Davis et al., 1985). The term job satisfaction refers to the attitude and feelings people have about their works. Positive and favourable attitudes towards the job indicates job satisfaction (Armstrong, 2006).

The industries are looking forward to inculcating spiritual practices to enhance the satisfaction level at the work place to build a healthy working environment and performance. To increase the level of job satisfaction organizations are very keen on spiritual sessions through which their respective employees realize the value, belief in work.

\section{Objective of the Study}

- $\quad$ To study the effect of spiritual belief on Job satisfaction level.

- To study the Gender difference in perceiving Spiritual belief and Job satisfaction.

\section{Hypothesis}

- There is no significant relationship between Spirituality and Job satisfaction.

- There is no significant gender difference in perceiving Spiritual belief and Job Satisfaction.

\section{Research Design}

The present study has an exploratory research design

\section{Sample}

The sample consisted of 200 employees from education and Manufacturing sectors. Purposive sampling technique was used to collect the data. The participants' age range was between 25-66 years, belonging to different education and manufacturing sectors.

\section{Inclusion Criteria}

- Employees having minimum knowledge of communication.

- Employees with the minimum job experience of one year.

\section{Exclusion Criteria}

- Employee's educational level.

- Employee's demographic details.

\section{Variables}

- Independent variables: Spiritual Dimensions, age

- Dependent variables: Job satisfaction level

\section{Measuring Tool}

The sample was administered Spiritual Index scale developed by Mahendran Pand the items are classified into 
five domains such as Transcendence, Belongingness, self-esteem, Naturalness and Religiousness. Job satisfaction scale was administered on the sample.

\section{Procedure}

The study was conducted by employees of the education sector and small-scale manufacturing industries. Prior consent was taken from the respective organizations before administering the survey and the prior rapport was established with the sample and was given proper instructions to attend the scales and wherever the necessary items were transformed into their convenient language to facilitate the sample for the better understanding of the items.

\section{RESULTS AND DISCUSSIONS}

Table 1: Relationship between Spiritual Dimensions and Job Satisfaction

\begin{tabular}{|c|c|c|c|c|c|c|c|}
\hline Factors & & Transcendence & Belongingness & Self-Esteem & Naturalness & Religiousness & JS \\
\hline \multirow{3}{*}{ Transcendence } & Pearson Correlation & 1 & $.423^{* 8}$ & $.513^{* 8}$ & $.316^{* *}$ & $.523^{88}$ & $.619^{* *}$ \\
\hline & Sig. (2-tailed) & & .000 & .000 & .000 & .000 & .000 \\
\hline & $\mathrm{N}$ & 200 & 200 & 200 & 200 & 200 & 200 \\
\hline \multirow{3}{*}{ Belongingness } & Pearson Correlation & $.423^{* *}$ & 1 & $.518^{* *}$ & $.376^{* *}$ & $.514^{* *}$ & $.450^{* *}$ \\
\hline & Sig. (2-tailed) & .000 & & .000 & .000 & .000 & .000 \\
\hline & $\mathrm{N}$ & 200 & 200 & 200 & 200 & 200 & 200 \\
\hline \multirow{3}{*}{ Self-esteem } & Pearson Correlation & $.513^{* *}$ & $.518^{* *}$ & 1 & $.357^{* *}$ & $.750^{* *}$ & $.690^{* *}$ \\
\hline & Sig. (2-tailed) & .000 & .000 & & .000 & .000 & .000 \\
\hline & $\mathrm{N}$ & 200 & 200 & 200 & 200 & 200 & 200 \\
\hline \multirow{3}{*}{ Naturalness } & Pearson Correlation & $.316^{* *}$ & $.376^{* *}$ & $.357^{* *}$ & 1 & $.524^{* *}$ & $.396^{* *}$ \\
\hline & Sig. (2-tailed) & .000 & .000 & .000 & & .000 & .000 \\
\hline & $\mathrm{N}$ & 200 & 200 & 200 & 200 & 200 & 200 \\
\hline \multirow{3}{*}{ Religiousness } & Pearson Correlation & $.523^{* *}$ & $.514^{* *}$ & $.750^{* 8}$ & $.524^{* 8}$ & 1 & $.670^{8 *}$ \\
\hline & Sig. (2-tailed) & .000 & .000 & .000 & .000 & & .000 \\
\hline & $\mathrm{N}$ & 200 & 200 & 200 & 200 & 200 & 200 \\
\hline \multirow{3}{*}{ JS } & Pearson Correlation & $.619^{* *}$ & $.450^{* *}$ & $.690^{* 8}$ & $.396^{* 8}$ & $.670^{* 8}$ & 1 \\
\hline & Sig. (2-tailed) & .000 & .000 & .000 & .000 & .000 & \\
\hline & $\mathrm{N}$ & 200 & 200 & 200 & 200 & 200 & 200 \\
\hline
\end{tabular}

The primary objective of the present study was to study the relationship between Spiritual belief and Job Satisfaction and Table1shows the correlation between Spiritual dimensions, namely Transcendence, Belongingness, Self-esteem, Naturalness and Religiousness and Job satisfaction. The obtained Correlation indicates that there is a significant positive relationship between Spiritual belief and the Job satisfaction hence, the null hypothesis that states "there is no significant relationship between spiritual belief and job satisfaction" is rejected.

The result of the present study is in accordance with the findings of the earlier research conducted by Recker and Cousins, (1979) which postulates that meaning and purpose in life have been found to be positively related to aspects such as self-esteem, internal locus of control and general life satisfaction are positively related to job satisfaction.

A study by Sawatzky, Ratner \& Chiu (2005) have found a relationship between Quality of life (or life satisfaction) and Spirituality and postulated that Spirituality assists individuals to experience life satisfaction, which in turn has a positive influence on the Individual's experience of Job satisfaction. Garcia - Zamor (2003) states that Spirituality in the workplace creates a new organizational culture in which individual feel happier.

There could be many reasons (such as connecting one's self with the nature, trying to find meaning in present life etc.) for being influenced by spiritual belief and those set of belief systems influences Individual's satisfaction level at work place. 
Table 2: Mean Score and $t$ Value for Spirituality and Job Satisfaction between Male and Female

\begin{tabular}{|c|c|c|c|c|c|c|c|}
\hline Sl.No & Factor & Gender & $\mathbf{N}$ & Mean & SD & 't' value & Significant \\
\hline \multirow{2}{*}{1} & \multirow{2}{*}{ Transcendence } & Male & 138 & 24.35 & 4.01 & \multirow{2}{*}{-3.903} & \multirow{2}{*}{ Not Significant } \\
\hline & & Female & 62 & 26.73 & 3.91 & & \\
\hline \multirow{2}{*}{2} & \multirow{2}{*}{ Belongingness } & Male & 138 & 26.03 & 4.10 & \multirow{2}{*}{-.562} & \multirow{2}{*}{ Not Significant } \\
\hline & & Female & 62 & 26.39 & 4.31 & & \\
\hline \multirow{2}{*}{3} & \multirow{2}{*}{ Self - Esteem } & Male & 138 & 24.01 & 4.40 & \multirow{2}{*}{-.773} & \multirow{2}{*}{ Not Significant } \\
\hline & & Female & 62 & 24.53 & 4.51 & & \\
\hline \multirow{2}{*}{4} & \multirow{2}{*}{ Naturalness } & Male & 138 & 25.76 & 3.73 & \multirow{2}{*}{-.775} & \multirow{2}{*}{ Not Significant } \\
\hline & & Female & 62 & 26.19 & 3.46 & & \\
\hline \multirow{2}{*}{5} & \multirow{2}{*}{ Religiousness } & Male & 138 & 23.46 & 5.27 & \multirow{2}{*}{-2.920} & \multirow{2}{*}{ Not Significant } \\
\hline & & Female & 62 & 25.79 & 5.12 & & \\
\hline \multirow{2}{*}{6} & \multirow{2}{*}{ Job Satisfaction } & Male & 138 & 73.06 & 2.69 & \multirow{2}{*}{-2.359} & \multirow{2}{*}{ Not Significant } \\
\hline & & Female & 62 & 74.13 & 3.50 & & \\
\hline
\end{tabular}

The secondary objective of the study was to study the Gender differences in perceiving Spiritual belief and Job Satisfaction, with the reference to Table 2, it shows that there is no significant gender differences in experiencing Job Satisfaction and Belongingness, Self - Esteem, Naturalness with reference to Spiritual belief. It is found that there is a significant gender difference in perceiving Transcendence (Mean value for males is $24.35 \& 26.73$ for females) and Religiousness (Mean value for males is $23.46 \& 25.79$ for females) wherein females are more into these respective dimensions of Spiritual belief than males.

The present findings are accordance with the many previous studies carried out such as a study by Stephen A. et al, (2011) has found a significant gender difference in experiencing religiousness. A study by Maselko J and Kubzansky (2006) have found a significant difference in experiencing spirituality and religious practice.

\section{CONCLUSIONS}

The results of the study illustrate that there is a significant relationship between Spiritual belief and Job satisfaction and to certain extent women are more prone towards Transcendence and Religiousness.

\section{REFERENCES}

1. Michael M. Gruneberg, Toby D. Wall, (1984) Social psychology and organizational Behavior,

2. Donald K. Freedheim, Irving B. Weiner, Walter C. Borman, Daniel R. Ilgen, Richard J. Klimoski, Wiley (2003) Handbook of Psychology: Industrial and organizational psychology,

3. Mats Alvesson (2002) Understanding organizational culture, SAGE Publications Ltd

4. Neal M. Ashkanasy, Celeste Wilderom, Mark F. Peterson(2000) Hand Book of organizational culture and climate, SAGE Publications Ltd

5. Jyothi, P., \& Neelakantan, S. I. T. A. (2013). Quality of Work Life and Acedamic Dual-Career Couples Job Satisfaction. International Journal of Business and General Management, 2(4), 11-20.

6. Michael Carroll (1996) Workplace counseling: a systematic approach to employee care SAGE Publications Ltd

7. S. K. Srivastava (2005) Organizational Behavior and Management, Sarup \& Sons,

8. Jon L. Pierce, Donald G. Gardner, Randall B. Dunham (2001) Management and Organizational Behavior: An integrated perspective : South-Western College Publication 
9. Duane P. Schultz, Sydney Ellen Schultz(2009) Psychology and Work today: An introduction to Industrial and Organizational Psychology: Prentice Hall publisher

10. John A. Wagner III (2009) Organizational Behavior: Securing Competitive Advantage Taylor and Francis Publishers

11. Belias, D. I. M. I. T. R. I. O. S., \& Koustelios, A. T. H. A. N. A. S. I. O. S. (2013). Organizational culture of Greek banking institutions: a case study. International Journal of Human Resource Management and Research, 3(2), 95-104.

12. Schein E.(1968) : Organizational Socialization and the profession of Management: Industrial Preview 
